'Departamento de Medicina de Urgencia Clínica Las Condes. Santiago, Chile.

2Departamento de Anestesiología Clínica Las Condes. Unidad de ECMO. Santiago, Chile.

Los autores declaran no tener conflictos de interés. El trabajo no recibió financiamiento externo.

Recibido el 27 de noviembre de 2017, aceptado el 8 de marzo de 2018.

Correspondencia a: Dr. Rodrigo Díaz. Estoril 450, Santiago, Chile. rdiaz@clc.cl

\section{Reanimación cardiopulmonar extracorpórea. Caso clínico de paro cardiaco extra hospitalario}

\author{
LUIS HERRADA ${ }^{1}$, JOSÉ LUIS SANTELICES ${ }^{1}$, \\ RODRIGO ORREGO ${ }^{2}$, RODRIGO DÍAZ ${ }^{2}$
}

\section{Extracorporeal cardiopulmonay resuscitation: case report on an out-of-hospital cardiopulmonary arrest}

Out-of-hospital cardiopulmonary arrest (OHCA) is highly lethal. Although overall survival is increasing, hospital discharge with good neurological prognosis remains low and highly variable. In some countries, protocols are being implemented, which include techniques in cardiopulmonary resuscitation, allowing a better neurological prognosis for those patients who undergo an OHCA. Following these new techniques and the incorporation of these new protocols already accepted in the guidelines of advanced cardiopulmonary resuscitation, we report a 54 years old male who presented an OHCA and received advanced cardiopulmonary by a professional team in situ. He was transferred to the emergency department, where optimal advanced resuscitation was continued, until the connection to extracorporeal cardiopulmonary support, with the aim of reestablishing blood flow, a technique known as cardiopulmonary resuscitation (ECPR: extracorporeal cardiopulmonary resuscitation). The patient was discharged from the hospital 25 days later.

(Rev Med Chile 2018; 146: 260-265)

Key words: Emergency Medical Services; Extracorporeal Membrane Oxygenation; Out-of-Hospital Cardiac Arrest.
E l paro cardíaco extrahospitalario (PCR EH) es un problema de salud pública, que luego de décadas de desarrollo aún mantiene una alta tasa de mortalidad. Extrapolando datos internacionales ${ }^{1}$, la estimación de la incidencia para la Región Metropolitana sería de 9 casos al día. La tasa de sobrevida global en el registro CARES (Cardiac Arrest Registry to Enhance Survival) es cercana a $30 \%$, siendo extremadamente variable por las características que rodean al paro extrahospitalario ${ }^{2}$.

La cadena de supervivencia requiere de una serie de intervenciones secuenciales para asegurar la continuidad de la atención de las víctimas. En Chile aún son limitadas las intervenciones en esta cadena, como el conocimiento de reanimación básica en la comunidad y distribución de desfibrilador externo automático en lugares estratégicos. Sin embargo, en países que ya han implementado estas medidas, la sobrevida de los pacientes con PCR EH sigue manteniéndose en cifras bajas. Esto se debe a que, en un paro cardiorrespiratorio, la probabilidad de recuperar la circulación espontánea, disminuye rápidamente a medida que avanza el tiempo de reanimación y es casi imposible recuperarla después de $30 \mathrm{~min}$ de reanimación convencional ${ }^{3}$, debido principalmente a la persistencia de acidosis metabólica severa o de trastornos como trombo embolismo pulmonar $\mathrm{u}$ oclusión coronaria aguda, donde a pesar de una 
reanimación adecuada, mantener una adecuada perfusión de órganos no es posible.

El pronóstico neurológico también se hace ominoso a medida que avanza la reanimación ${ }^{4}$.

El ECMO (del inglés Extracorporeal Membrane Oxygenation), de acuerdo a las últimas guías de reanimación cardiopulmonar avanzada, ha sido recomendado para sustituir de forma total la función cardiaca y pulmonar durante una reanimación cardiaca de buena calidad y en presencia de una causa potencialmente reversible. Este soporte extracorpóreo durante la reanimación (ECPR, Extracorporeal Cardiopulmonary Resuscitation) permite reestablecer la entrega de oxigeno sistémico y una adecuada perfusión cerebral y coronaria, disminuyendo la mortalidad, mejorando el pronóstico neurológico, entregando el tiempo necesario para realizar las intervenciones que permitirán resolver la causa original del PCR o establecer el pronóstico neurológico, función de órganos terminales y función cardiaca con todos los elementos necesarios para esto.

A continuación, presentamos un caso de PCR EH en fibrilación ventricular refractaria, beneficiado de una reanimación avanzada óptima entregada por un equipo in situ y en el servicio de urgencia al cuál fue trasladado, donde se conectó con éxito a un soporte cardiopulmonar extracorpóreo para continuar la reanimación (ECPR).

\section{Caso clínico}

Hombre de 54 años con antecedentes médicos de válvula aórtica bicúspide, en 1994 presentó cuadro de endocarditis infecciosa, evolucionando con insuficiencia valvular aórtica, mitral y tricúspidea severa. En el año 2003, se hizo reemplazo valvular con prótesis mecánicas, evolucionando favorablemente, con vida activa, trabajando y capacidad funcional normal.

El día 27 de enero del 2017 a las 12:20 pm, mientras se encontraba en su trabajo en un edificio en construcción en el tercer piso, presentó compromiso de conciencia súbito. Testigo entrenado en reanimación cardiopulmonar básica, constató ausencia de respuesta y respiración anormal, solicitó una ambulancia y comenzó a realizar compresiones torácicas. Al momento de la llegada del equipo de rescate, se constató ausencia de pulso y respiración, ritmo inicial fibrilación ventricu- lar (FV), por esta razón se aplicó una descarga eléctrica de 200 joules con un monitor bifásico, inmediatamente después se instaló dispositivo de compresión mecánica (LUCAS ${ }^{\circledast}$ II). Siguiendo el protocolo de reanimación habitual, se administró epinefrina $1 \mathrm{mg}$ endovenoso (ev) (la cual se administró cada $5 \mathrm{~min}$, total $4 \mathrm{mg}$ ) y se realizó intubación endotraqueal.

Luego de 2 min de compresiones torácicas se constató la ausencia de pulso, con persistencia de la FV, por lo que nuevamente se aplicó descarga eléctrica con 200 joules, inmediatamente después se administró amiodarona $300 \mathrm{mg}$ ev, se continuó con compresiones torácicas continuas, se reevaluó a los $2 \mathrm{~min}$, continuando con $\mathrm{FV}$, se aplicó descarga eléctrica con 360 joules y se administró lidocaína $100 \mathrm{mg}$ ev. Después de otros 2 min de compresiones se reevaluó ritmo paciente por cuarta vez, persistiendo en FV. Se repitió una descarga eléctrica de 360 joules y se administró $150 \mathrm{mg}$ de amiodarona ev. Se decidió, dada la situación,el traslado del paciente en PCR $\mathrm{EH}$ al servicio de urgencia, solicitando presencia de equipo de ECMO por posible candidato a reanimación extracorpórea. Se evacuó al paciente desde el tercer piso, para lo que se utilizó material para inmovilización y el dispositivo de compresión mecánica LUCAS ${ }^{\oplus}$ II que mantuvo al paciente con compresiones continuas durante todo el procedimiento de rescate (Figura 1).

A la llegada del paciente tanto el equipo de urgencia como el equipo de ECMO se encontraban constituidos en el box de reanimación. El equipo de ECMO evaluó al paciente de acuerdo a protocolo establecido en la institución y confirmó al paciente como candidato a soporte extracorpóreo. (Figura 2).

Se comenzó el proceso de canulación guiada por ultrasonido por equipo ECMO, se mantuvo reanimación convencional avanzada por parte de los médicos de urgencia, guiada por presión arterial invasiva (presión arterial diastólica $>30 \mathrm{mmHg}$ ) y capnometría (> $25 \mathrm{mmHg}$ ), no se administran más drogas ev. Se instaló por vía percutánea una cánula 15 Fr en arteria femoral izquierda y una cánula $24 \mathrm{Fr}$ en vena yugular interna derecha (imposible punción femoral por mala visualización y colapso venoso), se dio inicio al soporte extracorpóreo, reestableciendo el flujo sanguíneo después de 23 min desde el ingreso del paciente al box de reanimación (Tabla 1). 

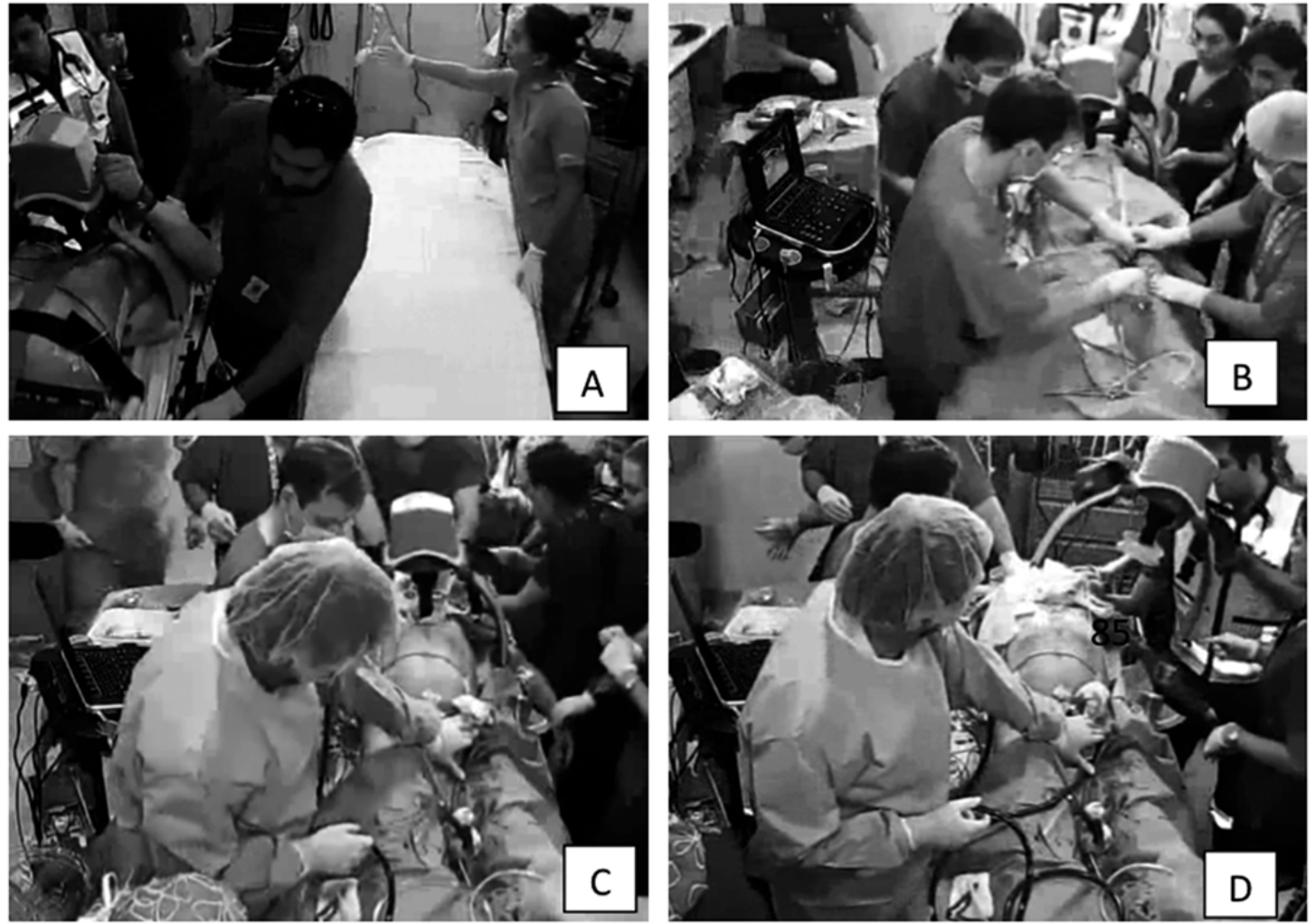

Figura 1. A: Paciente ingresa a reanimador con equipo de rescate con dispositivo de compresión mecánica instalado. B: Equipo ECMO comienza proceso de canulación del paciente percutánea guiada por ecografía. C: Comienza flujo a través de cánulas de ECMO. D: Se retira el dispositivo de compresiones mecánica.

Tabla 1. Tiempos de respuesta y sus intervalos desde el colapso del paciente hasta su traslado a pabellón

\begin{tabular}{|lcc|}
\hline Hitos de la reanimación & $\begin{array}{c}\text { Hora del día } \\
(\mathbf{2 4} \mathbf{~ h )}\end{array}$ & $\begin{array}{c}\text { Tiempo del intervalo } \\
\text { (min) }\end{array}$ \\
\hline Hora de colapso súbito presenciado & $12: 20$ & 0 \\
\hline Ingreso de la llamada a central de emergencia & $12: 23$ & 3 \\
\hline Salida de ambulancia medicalizada & $12: 24$ & 1 \\
Llegada al sitio de la emergencia & $12: 35$ & 11 \\
\hline Regreso desde el lugar de la emergencia hacia reanimador CLC & $12: 59$ & 24 \\
\hline Ingreso a reanimador CLC & $13: 08$ & 9 \\
\hline Inicio de la canulación & $13: 12$ & 4 \\
\hline Comienzo de ECMO* & $13: 35$ & 23 \\
\hline Hora de salida de urgencia & $13: 45$ & 10 \\
\hline Tiempo total & & 85 \\
\hline
\end{tabular}

*Se considera como hito el retiro del dispositivo de compresión mecánica. 
Figura 2. "Algoritmo PIENSA EN ECMO, se encuentra al interior del reanimador permite al equipo ECMO definir si el paciente es candidato a ECPR"
El paciente se trasladó desde urgencia a pabellón central, donde se realizó coronariografía que no mostró lesiones coronarias y se inició hipotermia controlada. Tras esto, se trasladó a rayos para confirmar posición de las cánulas y evaluar otras causas de paro, en tomografía axial de tórax se observó tromboembolismo de la arteria pulmonar izquierda y ramas segmentarias y subsegmentarias. Se debe mencionar que paciente evolucionó con hipokalemia de $2,93 \mathrm{mEq} / \mathrm{L}$ trastorno que podría facilitar la aparición de arritmias ventriculares. No es clara la causa del paro cardiorrespiratorio de este paciente.

El paciente ingresó a la unidad coronaria con fracción de eyección del ventrículo izquierdo de $20 \%$, con uso de drogas vasoactivas, con síndrome de distress respiratorio agudo que requirió ventilación mecánica invasiva y relajo 
neuromuscular, y disfunción renal que se apoyó con hemodiálisis.

Tras 5 días de soporte inotrópico decreciente y administración de levosimendan, se logró recuperar la función cardiaca, procediéndose al weaning y retiro del soporte extracorpóreo sin incidentes (total 6 días de ECMO). Dos días después del retiro del ECMO, se procede al weaning del ventilador y suspensión de la sedación, evidenciándose una recuperación neurológica completa (Score 1 según la escala CPC, cerebral performance categories).

La evolución posterior estuvo marcada por la instalación de un desfibrilador automático implantable con resincronizador debido a disfunción sistólica severa con bloqueo completo de rama izquierda y la normalización de la función renal 2 semanas después del PCR EH. El paciente es dado de alta a su domicilio 25 días después de haber sufrido PCR EH.

\section{Discusión}

El reporte de casos y publicaciones respecto al uso de ECPR ha aumentado en los últimos años, con resultados variables dependiendo de la experiencia de cada centro ${ }^{5}$. Incluso en algunos reportes instalando el ECMO en el mismo sitio del paro ${ }^{6}$. En Chile, no existe reporte de ningún caso de PCR EH reanimado con ECPR, es por esto que consideramos relevante compartir este caso.

La evidencia hasta ahora sugiere que, para lograr un aumento de la sobrevida global, es fundamental elegir adecuadamente a los pacientes y realizar la intervención lo antes posible cuando se sospeche que la causa del paro cardiorrespiratorio podría ser reversible.

Para que el proceso desde el inicio de la reanimación cardiopulmonar, hasta el inicio de ECPR, se realice de forma eficiente y en el menor tiempo posible, se debe implementar un programa ECMO dentro de la institución, y para que este programa de ECMO impacte en la recuperación de los pacientes, requiere un compromiso multidisciplinario y organizacional significativo para asegurar los recursos y personal necesarios.

El equipo ECMO trabaja en conjunto al equipo de medicina de urgencia y rescate durante la reanimación, luego continúan el soporte avanzado colaborando con intensivistas y cardiólogos en los cuidados críticos del paciente. Se requiere coordinación, preparación y capacitación continua del personal en manejo de recursos en crisis $^{7}$ (CRM-Crisis Resource Management), optimizando los tiempos y resultados. Es por eso que, además de las capacitaciones técnicas que se realizan para las Unidades de Cuidados Intensivos y Servicio de Urgencia, se considera fundamental la realización de simulaciones de alta fidelidad y la educación continua de los protocolos de manejo de recursos en crisis, que son llevados a cabo por parte del Equipo de ECMO con el objetivo de fortalecer el trabajo en equipo ${ }^{8}$.

Intervenciones como el ECPR, dan oportunidad de vida en buenas condiciones a pacientes que en otras circunstancias morirían, es una técnica promisoria y que crece rápidamente en el mundo. Aunque para lograr buenos resultados se debe fortalecer la cadena de supervivencia previa al ECMO. Actualmente se está llevando a cabo en Praga un estudio controlado randomizado para estudiar el impacto del ECPR vs manejo convencional en PCR-EH de origen cardiaco?

\section{Referencias}

1. Berdowski J, Berg RA, Tijssen JG, Koster RW. Global incidences of out- of-hospital cardiac arrest and survival rates: systematic review of 67 prospective studies. Resuscitation 2010; 81: 1479-87.

2. McNally B, Robb R, Mehta M, Vellano K, Valderrama AL, Yoon PW, et al. Out-of-hospital cardiac arrest surveillance Cardiac Arrest Registry to Enhance Survival (CARES), United States, October 1, 2005-December 31, 2010. MMWR Surveill Summ 2011; 60 (8): 1-19.

3. Hajbaghery M, Mousavi G, Akbari H. Factors Influencing Survival after In-Hospital Cardiopulmonary Resuscitation. Resuscitation 2005; 66 (3): 317-21.

4. Kim YJ, Ahn S, Sohn CH, Seo DW, Lee YS, Lee JH, et al. Long-term neurological outcomes in patients after out-hospital cardiac arrest. Resuscitation 2016; 101: 1-5.

5. Blumenstein J, Leick J, Liebretrau C, Kempfert J, Gaede L, Gross S, et al. Extracorporeal life support in cardiovascular patients with observed refractory in-hospital cardiac arrest is associated with favourable short and long-term outcomes: a propensity-matched analysis. Eur. Heart J. Acute Cardiovasc. Care 2016; 5 (7): 13-22.

6. Lamhaut L, Hutin A, Puymirat E. Pre-Hospital Extracorporeal Cardio Pulmonary Resuscitation (ECPR) strategy for treatment of refractory out hospital cardiac arrest: an observational study and propensity analysis. Resuscitation 2017; 117: 109-17. 
7. Sancho R, Maestre JM, Del Moral I. Crisis management: the role of simulation in patient safety. Rev Esp Anestesiol Reanim 2011; 58 (Supl. 3): S50-6.

8. Zakhary B, Kam L, Kaufman B, Felner K. The utility of high-fidelity simulation for training critical care fellows in the management of extracorporeal membrane oxyge- nation emergencies: a randomized controlled trial. Crit Care Med 2017; 45: 1367-73.

9. Belohlavek J, Kucera K, Jarkovsky J. Hyperinvasive Approach in Cardiac Arrest. Clinical trials. Disponible en: http://clinicaltrials.gov/ct2/show/NCT01511666. [Consultado el 1 de febrero de 2018]. 